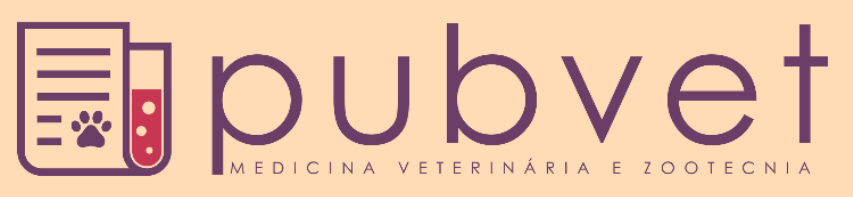

ISSN 1982-1263

https://doi.org/10.31533/pubvet.v13n2a272.1-8

\title{
Saccharomyces cerevisae na nutrição de ruminantes: Revisão
}

\author{
Joana Piagetti Noschang ${ }^{* \bullet}$, Ana Paula Schmidt ${ }^{1}$, Cássio Cassal Brauner ${ }^{2}$ \\ ${ }^{I}$ Mestranda na Universidade Federal de Pelotas, Programa de Pós-graduação em Zootecnia, Pelotas - RS Brasil \\ ${ }^{2}$ Professor da Universidade Federal de Pelotas, Departamento de Zootecnia, Pelotas -RS Brasil \\ *Autor para correspondência, E-mail: joana.piagetti@hotmail.com
}

Resumo. A utilização de aditivos na alimentação dos animais vem com o objetivo de melhorar a flora e o $\mathrm{pH}$ ruminal, aumentar a eficiência e a atividade dos microrganismos do rúmen. As condições do ambiente ruminal influenciam a flora microbiana e com isso a digestão dos alimentos. A levedura Saccharomyces cerevisae atua no controle dos parâmetros ruminais, tendo benefício sobre a digestão animal, melhora na fermentação ruminal, produção de leite, comportamento ingestivo, proporção de ácidos graxos de cadeira curta, redução de amônia, aumento da população microbiana e estabilização do pH e estes benefícios aumentam o desempenho produtivo dos ruminantes.

Palavras chave: aditivo, levedura, probiótico, rúmen, saúde

\section{Saccharomyces cerevisae in ruminant nutrition: Review}

\begin{abstract}
The use of additives in animal feed has been to improve ruminal flora and $\mathrm{pH}$, to increase the efficiency and activity of rumen microorganisms. The conditions of the ruminal environment influence the microbial flora and thus the digestion of food. The yeast Saccharomyces cerevisae acts to control the ruminal parameters, taking advantage of animal digestion, improving ruminal fermentation, milk production, ingestive behavior, stabilization of $\mathrm{pH}$ and these benefits performance of ruminants.
\end{abstract}

Keywords: additives, health, probiotic, rumen, yeast

\section{Saccharomyces cerevisae en la nutrición de rumiantes: Revisión}

Resumen. La utilización de aditivos en la alimentación de los animales tiene como objetivo mejorar la flora y el pH ruminal, aumentar la eficiencia y la actividad de los microorganismos del rumen. Las condiciones del ambiente ruminal influyen en la flora microbiana y con ello la digestión de los alimentos. La levadura Saccharomyces cerevisae actúa en el control de los parámetros ruminal, teniendo beneficio sobre la digestión animal, mejora en la fermentación ruminal, producción de leche, comportamiento ingestivo, proporción de ácidos grasos de silla corta, reducción de amoníaco, aumento de la población microbiana y estabilización del $\mathrm{pH}$ y estos beneficios aumentan el rendimiento productivo de los rumiantes.

Palabras clave: aditivo, levadura, probiótico, rumen, salud

\section{Introdução}

Durante o processo evolutivo os animais ruminantes desenvolveram a capacidade de aproveitar com maior eficiência os alimentos fibrosos como fonte energética e compostos nitrogenados não proteicos como fonte de proteína. Desta forma estes animais herbívoros tem a capacidade de transformar alimentos de baixo valor nutricional em produtos extremamente ricos para o consumo humano, como a 
carne e o leite. Isto porque eles apresentam estrutura anatômica do trato gastrointestinal diferenciada e da simbiose com microrganismos fermentadores deste tipo de alimento (Valadares Filho \& Pina, 2006). Estes animais possuem um estômago composto, multicavitário, formado por quatro compartimentos: rúmen, retículo, omaso e abomaso, nos quais a digestão fermentativa precede a digestão enzimática (Berchielli et al., 2011; Van Soest, 1994). O rúmen é o primeiro e mais importante compartimento do estômago dos ruminantes, possuindo volume de 100 e 10 litros para bovinos e ovinos adultos, respectivamente, ocupando grande porção da cavidade abdominal e representa até $10 \%$ do peso corporal (Hobson \& Stewart, 2012). O rúmen é uma câmara de fermentação e é considerado um ambiente único e diversificado, albergando um complexo ecossistema microbiano capaz de degradar paredes celulares vegetais (Kozloski, 2011). A contínua ingestão de alimento e a motilidade da parede ruminal, juntamente com a absorção ou passagem de metabólitos bacterianos resulta numa reposição contínua de substratos que permite o crescimento de uma população microbiana densa e diversificada (Berchielli et al., 2011).

A flora ruminal é composta de três grupos de microrganismos: bactérias, protozoários e fungos, os quais necessitam de condições específicas para o seu desenvolvimento adequado e sua sobrevivência no ambiente ruminal (Hobson \& Stewart, 2012). O rúmen tem como característica ser um ambiente anaeróbico, (baixa concentração de oxigênio), temperatura entre 38 a $42^{\circ} \mathrm{C}$, o pH pode variar de 5 a 7 (média 6,8), de acordo com o tipo de alimento ingerido, presença contínua de substratos e atividade fermentativa (Kozloski, 2011). Além disso, a quantidade de amônia presente no líquido ruminal também garante o desenvolvimento da microflora uma vez que a amônia é utilizada pelos microrganismos na síntese de proteína microbiana (Hungate, 1966). Sobre o aspecto nutricional a população microbiana tem três importantes funções para os animais: 1) a digestão e fermentação dos carboidratos, como celulose e amido, com consequente produção de ácidos graxos de cadeia curta AGCC 2) síntese de aminoácidos a partir de nitrogênio não proteico (NNP) proveniente da dieta ou da reciclagem da saliva e a partir da proteína dietética degradável no rúmen e 3) a síntese de vitaminas do complexo B e vitamina $\mathrm{K}$ (Berchielli et al., 2011). Diante disso, o ambiente ruminal e a ação da flora microbiana refletem em uma relação simbiótica e mutualística, ou seja, benéfica e recíproca entre os microrganismos e seu hospedeiro (Berchielli et al., 2011). Para que estes microrganismos sejam considerados espécies autóctones do rúmen, Hobson \& Stewart (2012) propuseram alguns critérios como: ser anaeróbio, estritos ou facultativos; apresentar proporção de $10^{6} / \mathrm{g}$ do conteúdo ruminal; ter sido isolado pelo menos dez vezes em dois ou mais animais; ter sido isolada em diferentes localizações geográficas e produzir subprodutos encontrados normalmente no rúmen.

Todavia, as populações de cada grupo de microrganismos e as espécies componentes destas são influenciadas diretamente pelo tipo de alimento fornecido ao hospedeiro (Van Soest, 1994), o que faz com que o rúmen apresente um ecossistema microbiano estável. Isto porque o ruminante saudável não sofre a contaminação do ecossistema, apesar de entrada de milhões de microrganismos no rúmen diariamente, pelos alimentos, água e ar e ao mesmo tempo dinâmico uma vez que sua população sofre mudanças de acordo com dieta do animal (Berchielli et al., 2011).

O número, a distribuição e a proporção relativa da população microbiana e das diferentes espécies de microrganismos ruminais são influenciados pela composição da dieta (Menezes et al., 2011), pois ela faz com que os microrganismos alterem o seu balanço fermentativo, seguido pelo ajuste das espécies microbianas às novas situações (Van Soest, 1994). Segundo Bergman (1990), os produtos finais da fermentação são parcialmente determinados pela natureza da dieta, que pode mudar a atividade metabólica dos microrganismos, provendo diferentes substratos que influenciam o número a quantidade e a natureza desses produtos. O microbioma ruminal é responsável pela fermentação dos alimentos e, estes microrganismos são sensíveis, principalmente, a oscilações de $\mathrm{pH}$. O fluído ruminal apresenta um pH fisiológico entre 6 e 7, sendo diretamente influenciado pela razão concentrado e volumoso da dieta que o animal recebe (Nagaraja et al., 1997).

\section{Bactérias ruminais}

As bactérias são os microrganismos mais ativos da atividade enzimática apresentando mais de 20 espécies já isoladas e representam a população mais diversa no rúmen, tanto em número de espécie quanto em capacidade metabólica (Hobson \& Stewart, 2012). Constituem de 60 a $90 \%$ da biomassa microbiana ruminal, representando $10^{10}-10^{11}$ bactérias $/ \mathrm{ml}$ de líquido ruminal (Arcuri et al., 2011) e em 
sua maioria composta por espécies anaeróbicas obrigatórias, podendo ser encontradas espécies anaeróbias facultativas. Estas últimas acabam por consumir o oxigênio do ambiente ruminal oriundo da alimentação e água consumidas na dieta. As bactérias variam em tamanhos (entre $1 \mathrm{a} 5 \mu \mathrm{m}$ ), na forma (cocos, bacilos e cocobacilos, que são as mais encontradas) e no tipo de parede celular, o que as classificam em gram-positivas ou gram-negativas. São gram-positivas ao possuírem uma membrana externa simples recoberta por uma camada espessa de glicopeptídios, já as bactérias gram-negativas possuem uma camada fina de glicopeptídios entre duas membranas (interna e externa) (Kozloski, 2011).

A degradação de alguns substratos (celulose, hemicelulose, lignina, amido, proteína e gordura) é realizada por um grupo de bactérias e a interação entre elas mesmas e outros grupos de microrganismos são responsáveis pelo efeito sinérgico na produção de AGCC e proteína microbiana no rúmen e, portanto, as bactérias do ambiente ruminal são classificadas de acordo com a atuação de cada grupo no processo fermentativo.

As bactérias fermentadoras de carboidratos fibrosos, também denominadas bactérias celulolíticas ou fibrolíticas, tem entre as principais espécies, a Ruminococcus flavefaciens, $R$. albus e Fibrobacter succinogenes e são classificadas como gram-positivas (Arcuri et al., 2011)). Estas hidrolisam a celulose por meio de complexos enzimáticos denominados celulases que, na maioria dos microrganismos celulolíticos, estão associadas às células, se aderem firmemente às partículas fibrosas do conteúdo ruminal (Berchielli et al., 2011) e tem como produtos, principalmente: acetato, propionato, butirato, succinato, formato, $\mathrm{CO}_{2}$ e $\mathrm{H}_{2} \mathrm{O}$ (Hungate, 1966). Algumas bactérias celulolíticas degradam apenas a hemicelulose e os produtos originados desta fermentação servem de substrato para outras espécies. Arcuri \& Mantovani (2006), também destacam outra espécie importante, a Butirivibrio fibrosolvens, que fermenta tanto celulose quanto hemicelulose e possui papel fundamental nos eventos de mudanças de dietas. As bactérias celulolíticas possuem taxa de crescimento lenta e para a síntese de proteína microbiana são dependentes da amônia e ácidos graxos de cadeia ramificada (Hobson \& Stewart, 2012). Bactérias fermentadoras de carboidratos não fibrosos ou bactérias amilolíticas são assim denominadas por associarem-se aos grânulos de amido e degradarem carboidratos de natureza não estrutural pelas enzimas amilase, assim como carboidratos solúveis como dextrinas, frutosanas e açúcares. Possuem taxa de crescimento mais elevada e utilizam amônia e aminoácidos para sintetizar proteínas. $\mathrm{Na}$ fermentação do amido e açúcares solúveis produzem acetato; porém, quando estes carboidratos são abundantes passam a produzir também propionato. São as bactérias de maior importância na produção de ácido propiônico (ácido graxo volátil de maior aproveitamento animal) e, portanto, toleram $\mathrm{pH}$ mais ácido $(5,8)$. As principais espécies deste grupo são Ruminobacter amylophilus, Streptococcus bovis, Lactobacillus sp e Prevotella sp., e são classificadas como gram-negativas (Hobson \& Stewart, 2012).

As bactérias proteolíticas são aquelas que degradam as proteínas. Algumas espécies de bactérias como B. amylophilus, B. ruminicola, Butirivibrio sp. e $S$. ruminantium tem a capacidade de degradar proteínas; porém, são incapazes de crescer tendo os aminoácido como único substrato. Peptostreptococci sp. e Clostridium aminophilum utilizam aminoácidos como principal substrato energético. Estas últimas não utilizam carboidratos como fonte de energia e degradam as proteínas mais intensamente que as demais (Kozloski, 2011).

Bactérias pectinogênicas atuam na fermentação da pectina, que apesar de ser um polímero estrutural, as bactérias peptinogênicas possuem características semelhantes às bactérias que atuam na degradação do amido. Succinivibrio dextrinosolvens é a principal bactéria classificada neste grupo.

As bactérias lácticas como Megasphaera elsdenii e Selenomonas ruminantium utilizam o ácido lático como principal substrato energético.

As bactérias metanogênicas possuem estrutura diferenciada em relação as demais bactérias ruminais, pela ausência da parede celular e pela composição da membrana que nestas são éteres de glicerol ao invés de ésteres. São organismos estritamente anaeróbicos capazes de produzir metano a partir de $\mathrm{CO}_{2}$ e $\mathrm{H}_{2}$. $\mathrm{O}$ gênero Methanobacterium é especialmente importante para o ecossistema ruminal, pois regula a fermentação removendo as moléculas de $\mathrm{H}_{2}$. A quantidade encontrada no rumem varia de $10^{7}$ a $10^{9}$ $\mathrm{cel} / \mathrm{ml}$ de líquido ruminal e depende do tipo da dieta dada ao animal, especialmente o conteúdo de fibra (Kamra, 2005). 
Já as bactérias lipolíticas atuam na hidrólise de triglicerídeos até glicerol e ácidos graxos. Um exemplo desse grupo é a Anaerovibrio lipolytica.

Existem também as bactérias anaeróbias facultativas (Lactobacillus sp., Streptococcus sp., e Enterobacter sp.), um grupo de bactérias distinto dos demais que associado principalmente à parede celular do rúmen digerem células epiteliais mortas e apresentam importante atividade ureolítica, presentes no ambiente da interfase entre o tecido bem oxigenado e o conteúdo ruminal anaeróbio (Arcuri et al., 2011; Arcuri \& Mantovani, 2006). Desempenham papel importante na manutenção de baixos níveis de oxigênio dissolvido no conteúdo ruminal.

\section{Protozoários ruminais}

Outro grupo de microrganismos do rúmen de grande importância são os protozoários. Estes são microrganismos unicelulares, anaeróbios e não patogênicos de estrutura complexa (boca, esôfago, estômago, reto e ânus) e em sua maioria ciliados (Dehority, 2003). Os protozoários representam de 40 a $60 \%$ da biomassa microbiana total do rúmen, em função do seu tamanho, que varia de 20 a $200 \mu \mathrm{m}$ (10 a100 vezes maiores que as bactérias) e aparecem em número de $10^{4}$ a $10^{6}$ células $/ \mathrm{ml}$ de fluido (Berchielli et al., 2011).

Os protozoários são divididos em dois grupos: os entodiniomorfos, que normalmente estão presentes quando em dietas a base de forragem, pois são capazes de aderirem-se às fibras e possuem atividade celulolítica e hemicelulolítica, ingerindo partículas insolúveis que ficam suspensas no fluido ruminal. E o grupo dos holotriquias que aparecem em maior número em dietas a base de concentrados e tem a capacidade de ingerir grânulos de amido (Kozloski, 2011). O perfil enzimático de protozoários holotriquia indica que eles têm amilase, invertase, esterase pectina e poligalacturonase podendo utilizar suficientes quantidades de amido, pectina e açúcar solúvel como fonte de energia e estão mais presentes quando em dietas a base de grãos (Williams \& Coleman, 1997). Os protozoários utilizam bactérias como principal fonte de aminoácidos e de ácidos nucléicos, sendo que o engolfamento é mais intenso em dietas ricas em grãos. Quando a dieta é rica em forragem, as bactérias constituem sítios de aderência e dificultam o engolfamento pelos protozoários. Ao engolfar os grânulos de amido, os protozoários os assimilam rapidamente e estocam na forma de amilopectina ou amido protozoário e os degradam mais lentamente que a degradação feita pelas bactérias, o que pode evitar a queda brusca do $\mathrm{pH}$ quando em dietas ricas em concentrados. Portanto, os protozoários desempenham um efeito tamponante, pois as bactérias não têm acesso a uma quantidade excessiva de substratos prontamente fermentáveis, consequentemente, a presença de protozoários no rúmen reduz o risco de acidose, em dietas ricas em grãos ou açúcares (Arcuri et al., 2011; Arcuri \& Mantovani, 2006; Kozloski, 2011).

Uma característica peculiar dos protozoários é o quimiotactismo, isto é, a capacidade de se locomoverem num gradiente de concentração de açúcares ou glicoproteínas (Arcuri \& Mantovani, 2006) e também a existência de uma relação inversa entre o número de protozoários e o número de bactérias na fase líquida ruminal em função da competição por alimentos e pela ação predatória dos protozoários sobre as bactérias (Coleman, 1964). De acordo com Williams \& Coleman (1997) a presença de protozoários no ambiente ruminal pode levar efeitos benéficos como a estabilidade da fermentação do $\mathrm{pH}$, aumentar a concentração de AGCCs, maior digestão do amido e efeitos adversos: maior concentração de amônia, maior atividade proteolítica, aumento da metanogênese, níveis plasmáticos de ácidos graxos saturados elevados, gordura na carcaça e susceptibilidade ao timpanismo.

\section{Sacharomyces cerevisae}

Os estudos em nutrição animal buscam ferramentas para aprimorar os sistemas nutricionais a fim de intensificar e explorar o máximo potencial produtivo dos ruminantes, e o fornecimento de dietas com alto teor de energia está cada vez mais presente, com o intuito de alcançar melhores índices produtivos (Valadares Filho et al., 2016). Entretanto, esta realidade pode acarretar em diversos transtornos para os animais, tais como o desequilíbrio dos microrganismos, tornando o animal mais susceptível a problemas metabólicos (Corrêa, 2010).

A troca brusca da dieta é uma prática comum em fazendas de ruminantes e é o principal fator que determina o grau de perturbação da fermentação ruminal e potenciais distúrbios digestivos (González et 
al., 2012; Nagaraja \& Titgemeyer, 2007). Isto porque os ruminantes são anatomicamente e fisiologicamente adaptados para uma dieta composta predominantemente por alimentos fibrosos (Nagaraja et al., 1997) e quando se oferece uma dieta com altos teores de grãos, pode-se desenvolver um desequilíbrio fermentativo denominado acidose ruminal, que dependendo da intensidade, pode-se apresentar de forma aguda ou subaguda (Lean et al., 2013).

A manipulação da fermentação ruminal tem o objetivo de controlar alguns processos metabólicos no rúmen, atingindo assim a utilização mais eficiente dos nutrientes (Nagaraja et al., 1997). A utilização de aditivos na alimentação dos animais vem sendo utilizada com o objetivo de melhorar a flora e o pH ruminal, aumentar a eficiência e a atividade dos microrganismos do rúmen (Awawdeh \& Obeidat, 2011; Carocho et al., 2014; Liu et al., 2016; Newbold \& Rode, 2006). De acordo com a Food and Drug Administration (FDA, 2015), os Direct Fed Microbial (DFM) são produtos que contêm microrganismos vivos (bactérias, fungos ou leveduras) e atualmente substituem a nomenclatura dos probióticos.

As leveduras vivas se destacam como o aditivo mais pesquisado (Desnoyers et al., 2009; Vohra et al., 2016). Sua utilização tem sido uma alternativa na mantença do ambiente ruminal frente às dietas ricas em carboidratos devido aos seus benefícios. Elas estimulam bactérias que utilizam ácido láctico e contribuem para o constante suprimento de nutrientes à população bacteriana no intestino e, com isso, aumentando a digestibilidade das fibras (Dawson, 2000). Dentre estas, é possível citar a Saccharomyces cerevisiae, muito estudada na nutrição de ruminantes como aditivo probiótico para controle dos parâmetros ruminais, tendo benefício sobre a digestão animal (Issakowicz et al., 2013; Lascano et al., 2009), melhorar a fermentação ruminal, produção de leite, comportamento ingestivo, proporção de ácidos graxos voláteis, redução de amônia, aumento da população microbiana e estabilização do $\mathrm{pH}$ (Chaucheyras-Durand et al., 2008; Yuan et al., 2015). A cultura de levedura é produto da fermentação natural contendo produtos da parede celular das leveduras, células, vitaminas, proteínas, peptídeos, aminoácidos, nucleotídeos, lipídeos, ácidos orgânicos, oligossacarídeos, ésteres e álcoois (Nocek et al., 2011). Na nutrição animal, as leveduras são excelentes fontes de nutrientes, fornecendo proteína, carboidrato e vitaminas do complexo B (Quigley, 2005). Sua utilização promove um aumento de $\mathrm{pH}$, do número de bactérias celulolíticas, da digestibilidade e do consumo de fibra, com consequente aumento na produção de leite, alteração nas concentrações de ácidos graxos voláteis e diminuição da produção de metano (Desnoyers et al., 2009). Os componentes dessa parede celular hidrolisada enzimaticamente, que contém mananos, glucanos e metabólitos da levedura, são adicionados ao meio de cultura, diferenciando dos produtos que possuem apenas a levedura viva e que devem estar viavéis para possuirem efeito direto no rúmen, com utilização de oxigênio (Marden et al., 2008).

Segundo Wallace (1994), as leveduras possuem um papel importante na remoção do oxigênio do ambiente ruminal, causando um aumento na viabilidade bacteriana e melhorando o metabolismo do lactato (Costa, 2004). O oxigênio é tóxico para as bactérias ruminais, já que inibe o crescimento bacteriano e a adesão das bactérias celulolíticas à fibra (Roger et al., 1990), diminuindo a eficiência do processo digestivo. Dessa forma, quando há adição de culturas de Saccharomyces cerevisiae à dieta de ruminantes, o número de bactérias no rúmen aumenta, pois a atividade das leveduras protege as bactérias anaeróbicas contra danos ocasionados pelo oxigênio, e proporciona uma melhor fermentação ruminal (Newbold et al., 1996).

O efeito quantitativo da suplementação com levedura é maior quando se utiliza uma dieta com maior proporção de concentrado, onde a digestibilidade de matéria orgânica também aumenta linearmente quanto maior for a dose de levedura fornecida (Desnoyers et al., 2009). Concentrações de $10^{4}$ a $10^{5}$ unidades formadoras de colônia (UFC) de Saccharomyces cerevisiae/mL de líquido ruminal são eficientes na estimulação do crescimento de bactérias ruminais (Dawson, 2000). Em estudo realizado por Tripathi \& Karim (2010) relataram outro efeito do uso de Saccharomyces cerevisiae na fermentação ruminal de ovinos fistulados, alimentados com uma dieta de alto teor de trigo. Os resultados obtidos demonstraram a eficiência da levedura na estabilização do $\mathrm{pH}$ ruminal por estimular protozoários ciliados que são capazes de consumir lactato e, além disso, digerir grânulos de amido rapidamente, competindo por esse substrato com bactérias amilolíticas. Ademais, os protozoários fermentam o amido mais lentamente do que bactérias amilolíticas, resultando em ácidos graxos voláteis como produtos finais da fermentação, ao invés de lactato. 
Desnoyers et al. (2009) realizaram uma metanálise com a reunião de 110 artigos e 157 experimentos, onde demonstraram que a suplementação com levedura aumentou o $\mathrm{pH}$ ruminal e a concentração de ácidos graxos voláteis no rúmen, e tendem a reduzir a concentração de ácido lático, não influenciando na razão acetato:propionado. Além disso, avaliaram o efeito da interação entre o fornecimento de levedura e as variações entre os experimentos, sendo concluído que, quanto maior for o consumo de matéria seca e maior a proporção de concentrado na dieta, maior será o efeito positivo da adição de levedura no controle do pH ruminal, e o efeito negativo na concentração de ácido lático é mais acentuado pela maior proporção de concentrado na dieta.

\section{Considerações finais}

A suplementação com leveduras vivas em dietas de ruminantes visa auxiliar no controle dos parâmetros ruminais em níveis favoráveis para manter o ambiente ruminal saudável, aumentando a ingestão e disponibilidade de nutrientes para o animal, levando a um maior desempenho produtivo. Todavia, os efeitos da levedura na fermentação ruminal e no desempenho dos animais, assim como seu mecanismo de ação, não estão totalmente evidentes. Há carência de estudos avaliando a suplementação de culturas de Saccharomyces cerevisiae ao metabolismo de ovinos e que envolvam a modificação da fermentação ruminal, como ocorre em mudanças abruptas de dietas.

\section{Referências bibliográficas}

Arcuri, P. B., Lopes, F. C. F. \& Carneiro, J. C. (2011). Microbiologia do rumen. In T. T. Berchielli, A. V. Pires \& S. G. Oliveira (Eds.), Nutrição de Ruminantes (pp. 115-148). Jaboticabal, Brazil: FUNEP.

Arcuri, P. B. \& Mantovani, H. C. (2006). Recentes avanços em microbiologia ruminal e intestinal:(BIO) tecnologias para a nutrição de ruminantes. Paper presented at the V Simpósio de Produção de Gado de Corte.

Awawdeh, M. S. \& Obeidat, B. S. (2011). Effect of supplemental exogenous enzymes on performance of finishing Awassi lambs fed olive cake-containing diets. Livestock Science, 138(1-3):20-24.

Berchielli, T. T., Pires, A. V. \& Oliveira, S. G. (2011). Nutrição de Ruminantes. Jaboticabal, Brazil: FUNEP.

Bergman, E. N. (1990). Energy contributions of volatile fatty acids from the gastrointestinal tract in various species. Physiological Reviews, 70(2):567-590.

Carocho, M., Barreiro, M. F., Morales, P. \& Ferreira, I. C. F. R. (2014). Adding molecules to food, pros and cons: A review on synthetic and natural food additives. Comprehensive Reviews in Food Science and Food Safety, 13(4):377-399.

Chaucheyras-Durand, F., Walker, N. D. \& Bach, A. (2008). Effects of active dry yeasts on the rumen microbial ecosystem: Past, present and future. Animal Feed Science and Technology, 145(1-4):5-26.

Coleman, G. S. (1964). The metabolism of Escherichia coli and other bacteria by Entodinium caudatum. Microbiology, 37(2):209-223.

Corrêa, M. N. (2010). Transtornos metabólicos nos animais domésticos. Pelotas, Rio Grande do Sul, Brasil: Editora e Gráfica Universitária - UFPEL.

Costa, L. F. (2004). Leveduras na nutrição animal. Revista Eletrônica Nutritime, 1(1):1-6.

Dawson, K. A. (2000). Some milestones in our understanding of yeast culture supplementation in ruminants and their implications in animal production systems. Paper presented at the Alltech's 16th Annu. Symp. Biotechnol. Feed Ind., Lexington, USA.

Dehority, B. A. (2003). Rumen microbiology. Notthingham, USA: University Press.

Desnoyers, M., Giger-Reverdin, S., Bertin, G., Duvaux-Ponter, C. \& Sauvant, D. (2009). Meta-analysis of the influence of Saccharomyces cerevisiae supplementation on ruminal parameters and milk production of ruminants. Journal of Dairy Science, 92(4):1620-1632.

FDA. (2015). Food and Drug Administration of the US, Substances used as GRAS in food. 21CFR 184.

González, L. A., Manteca, X., Calsamiglia, S., Schwartzkopf-Genswein, K. S. \& Ferret, A. (2012). Ruminal acidosis in feedlot cattle: Interplay between feed ingredients, rumen function and feeding behavior (a review). Animal Feed Science and Technology, 172(1-2):66-79.. 
Hobson, P. N. \& Stewart, C. S. (2012). Rumen Microbial Ecosystem (2 ed.). Londo, UK: Blackie Academic \& Professional.

Hungate, R. E. (1966). The rumen and its microbes Academic Press New York and London. New York, Estados Unidos: Academic Press.

Issakowicz, J., Bueno, M. S., Sampaio, A. C. K. \& Duarte, K. M. R. (2013). Effect of concentrate level and live yeast (Saccharomyces cerevisiae) supplementation on Texel lamb performance and carcass characteristics. Livestock Science, 155(1):44-52.

Kamra, D. N. (2005). Rumen microbial ecosystem. Current Science, 89(1):124-135.

Kozloski, G. V. (2011). Bioquímica dos ruminantes (3a Ed. ed. Vol. 1). Santa Maria: Editora Universidade Federal de Santa Maria.

Lascano, G. J., Zanton, G. I. \& Heinrichs, A. J. (2009). Concentrate levels and Saccharomyces cerevisiae affect rumen fluid-associated bacteria numbers in dairy heifers. Livestock Science, 126(1-3):189194.

Lean, I. J., Van Saun, R. \& DeGaris, P. J. (2013). Energy and protein nutrition management of transition dairy cows. Veterinary Clinics: Food Animal Practice, 29(2):337-366.

Liu, Q. H., Shao, T. \& Bai, Y. F. (2016). The effect of fibrolytic enzyme, Lactobacillus plantarum and two food antioxidants on the fermentation quality, alpha-tocopherol and beta-carotene of high moisture napier grass silage ensiled at different temperatures. Animal Feed Science and Technology, 221, Part A1-11.

Marden, J. P., Julien, C., Monteils, V., Auclair, E., Moncoulon, R. \& Bayourthe, C. (2008). How does live yeast differ from sodium bicarbonate to stabilize ruminal $\mathrm{pH}$ in high-yielding dairy cows? Journal of Dairy Science, 91(9):3528-3535.

Menezes, A. B., Lewis, E., O'Donovan, M., O'Neill, B. F., Clipson, N. \& Doyle, E. M. (2011). Microbiome analysis of dairy cows fed pasture or total mixed ration diets. FEMS Microbiology Ecology, 78(2):256-265.

Nagaraja, T. G., Newbold, C. J., Van Nevel, C. J. \& Demeyer, D. I. (1997). Manipulation of ruminal fermentation The rumen microbial ecosystem (pp. 523-632): Springer.

Nagaraja, T. G. \& Titgemeyer, E. C. (2007). Ruminal acidosis in beef cattle: The current microbiological and nutritional outlook. Journal of Dairy Science, 90(Supp):E17-E38.

Newbold, C. J. \& Rode, L. M. (2006). Dietary additives to control methanogenesis in the rumen. International Congress Series, 1293(0):138-147.

Newbold, C. J., Wallace, R. J. \& McIntosh, F. M. (1996). Mode of action of the yeast Saccharomyces cerevisiae as a feed additive for ruminants. British Journal of Nutrition, 76(2):249-261.

Nocek, J. E., Holt, M. G. \& Oppy, J. (2011). Effects of supplementation with yeast culture and enzymatically hydrolyzed yeast on performance of early lactation dairy cattle. Journal of Dairy Science, 94(8):4046-4056.

Quigley, J. D. (2005). Mannan-oligosaccharides and other non-antibiotic alternatives to the management of enteric disease of cattle. Paper presented at the Proceedings of the 38th Annual Convention of the American Association of Bovine Practitioners, Salt Lake City, Utah, USA.

Roger, V., Fonty, G., Komisarczuk-Bony, S. \& Gouet, P. (1990). Effects of physicochemical factors on the adhesion to cellulose avicel of the ruminal bacteria Ruminococcus flavefaciens and Fibrobacter succinogenes subsp. succinogenes. Applied and Environmental Microbiology, 56(10):3081-3087.

Tripathi, M. K. \& Karim, S. A. (2010). Effect of individual and mixed live yeast culture feeding on growth performance, nutrient utilization and microbial crude protein synthesis in lambs. Animal Feed Science and Technology, 155(2-4):163-171.

Valadares Filho, S. C. \& Pina, D. S. 2006. Fermentação Ruminal. In: Nutrição de Ruminantes. Jaboticabal: Funep.

Valadares Filho, S. C., Costa e Silva, L. F., Gionbelli, M. P., Rotta, P. P., Marcondes, M. I., Chizzotti, M. L. \& Prados, L. F. (2016). Exigências nutricionais de zebuínos puros e cruzado - BR-Corte (Vol. 1). Viçosa, Minas Gerais: Universidade Federal de Viçosa. 
Van Soest, P. J. (1994). Nutritional ecology of the ruminant (Vol. 1). Ithaca, NY, USA: Cornell University Press.

Vohra, A., Syal, P. \& Madan, A. (2016). Probiotic yeasts in livestock sector. Animal Feed Science and Technology, 21931-47.

Wallace, R. J. (1994). Ruminal microbiology, biotechnology, and ruminant nutrition: progress and problems. Journal of Animal Science, 72(11):2992-3003.

Williams, A. G. \& Coleman, G. S. (1997). The rumen protozoa. In P. N. Hobson \& C. S. Stewart (Eds.), The rumen microbial ecosystem (Vol. 2, pp. 73-139). London, UK: Blackie Academic \& Professional.

Yuan, K., Liang, T., Muckey, M. B., Mendonça, L. G. D., Hulbert, L. E., Elrod, C. C. \& Bradford, B. J. (2015). Yeast product supplementation modulated feeding behavior and metabolism in transition dairy cows. Journal of Dairy Science, 98(1):532-540.

Recebido: 21 de dezembro, 2019.

Aprovado: 4 de janeiro, 2019.

Publicado: 27 de fevereiro, 2019

Licenciamento: Este artigo é publicado na modalidade Acesso Aberto sob a licença Creative Commons Atribuição 4.0 (CC-BY 4.0), a qual permite uso irrestrito, distribuição, reprodução em qualquer meio, desde que o autor e a fonte sejam devidamente creditados. 